\title{
Associação timoma e estrongiloidíase intestinal grave
}

\author{
Thymoma and severe intestinal strongyloidiasis association \\ Pérsio Godoy, Christion Marcellus Comargos Compos, Guilherme Costo \\ e Lúcio Porto Fonseco de Costro
}

Resumo Os autores relatam o caso de um homem de 59 anos de idade com timoma e estrongiloidíase intestinal grave. São revistos aspectos da resposta imunitária relacionados ao tumor e, possivelmente, implicados no desenvolvimento da hiperinfecção pelo Strongyloides stercoralis.

Palavras-chaves: Timoma e estrongiloidiase. Strongyloides stercoralis. Timoma

Abstract A 59-years-old man with thymoma and severe intestinal strongyloidiasis is reported. The authors pointed out a possible influence of immunological response related with thymoma in the development of hyperinfection by Strongyloides stercoralis.

Key-words: Thymoma and strongyloidiasis. Strongyloides stercoralis. Thymoma

\footnotetext{
Departamento de Anatomia Patológica e Medicina Legal da Faculdade de Medicina da Universidade Federal de Minas Gerais, Belo Horizonte, MG,Brasil

Endereço para correspondência: Dr. Pérsio Godoy. Deptº de Anatomia Patológica e Medicina Legal/FM/UFMG. Av. Prof. Alfredo Balena 190, 5ㅇaㅁ, 30130-100 Belo Horizonte, MG.

Fax: (031) 222-3987.

Recebido para publicação em 08/07/96.
} 
A associação timoma e estrongiloidíase não parece representar mera casualidade, embora assim considerado no único caso localizado na literatura consultada6.

O timoma tem sido responsabilizado por infecções oportunísticas devido a insuficiência da resposta imunitária celular, cuja patogênese não está bem esclarecida. Alem disso, constitui relevante fator a hipogamaglobulinemia, presente em 5\% dos casos desse tumor7 1718 .

Por seu turno, é bem reconhecida a ocorrência de formas graves de estrongiloidíase em pacientes imunodeprimidos 412 15, não obstante sua prevalência na SIDA permaneça controvertida2. Em tais circunstâncias, surge hiperativação da auto-infecção e conseqüente invasão larvária maciça do intestino grosso, com a possibilidade do desenvolvimento de lesões extra-intestinais pela disseminação linfohematogênica 4 .

\section{RELATO DO CASO}

Homem de 59 anos de idade. Relatava à admissão (02.10.1984) tosse seca, adinamia e emagrecimento há dezoito meses, somando-se nos últimos três meses dor torácica e febre; quinze dias antes da internação intensificaramse os sintomas e surgiu expectoração purulenta. Constipação intestinal constituiu a única queixa digestiva de caráter persistente nos derradeiros três anos. Medicado com penicilina e cloranfenicol, sem resposta. Consciente, desnutrido, desidratado, mucosas hipocoradas $(+++/ 4+)$, afebril, taquipnéico $(F R=28)$, crepitações inspiratórias e expiratórias difusas e bilaterais, taquicárdico $(F C=130)$, hipotenso $(\mathrm{PA}=90 \times 60 \mathrm{mmHg}$ ), edema dos MMII $(++/ 4+)$; jugulares engurgitadas e lobo esquerdo do fígado palpável à $6 \mathrm{~cm}$ do apêndice xifóide. Ocorreu agravamento progressivo do quadro respiratório, aparecendo, ainda, numerosos episódios de diarréia, predominantemente do tipo alto. Óbito em 08.10.1984, com os diagnósticos clínicos prováveis de tuberculose pulmonar, câncer broncopulmonar, DPOC, cor pulmonale crônico e anemia a esclarecer.

Exames complementares. $\mathrm{Rx}$ de tórax: massa mediastinal de limites imprecisos, com projeção principalmente para esquerda e áreas de condensação, confluentes no pulmão direito e não confluentes à esquerda. Anemia $(1.700 .000$ hemácias $\mathrm{mm}^{3}$; hemoglobina $=4,9 \mathrm{~g} \%$; hematócrito $=14 \%$ ); leucocitos total: $5.100 \mathrm{~mm}^{3}$, eosinófilos: ausentes; proteínas totais: 4,9g\%, albumina: $3,8 \mathrm{~g} \%$ e globulinas: $1,1 \mathrm{~g} \%$.

Laudo da necrópsia. Timoma encapsulado (Figura 1), não invasivo, misto (tipo cortical e medular), com infiltração linfocitária moderada (Figura 2), localizado no mediastino, imediatamente anterior à bifurcação traqueal $(6,5 \times 6,0 \times 4,0 \mathrm{~cm})$.

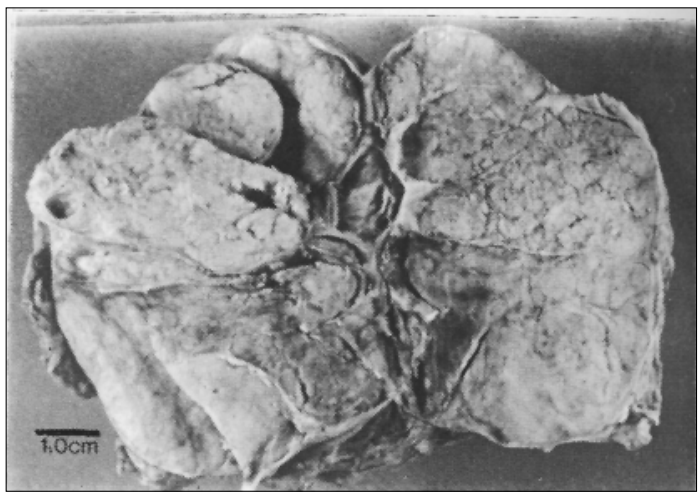

Figura 1 - Timoma. Aspecto macroscópico.

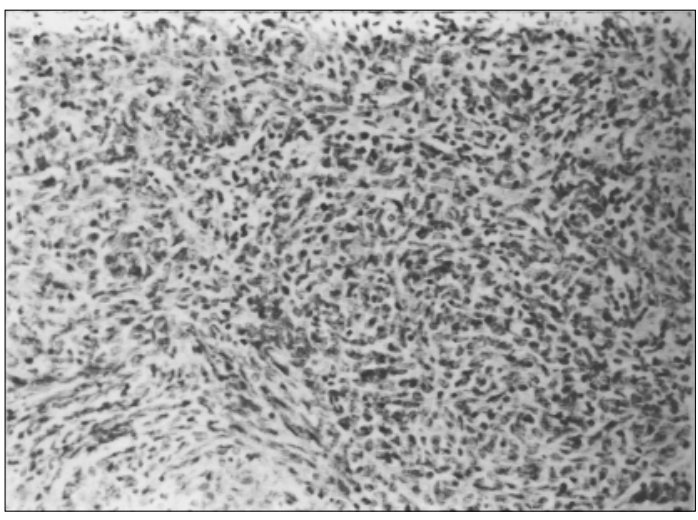

Figura 2 - Timoma misto, com células poligonais e fusiformes, além de infiltração linfocitária, HE, $250 X$

Broncopneumonia purulenta em pequenos focos disseminados bilateralmente e pseudolobar no lobo superior e médio direitos. Hemorragia pulmonar multifocal.

Estrongiloidíase intestinal grave, caracterizada no delgado por intenso infiltrado inflamatório 
crônico, predominantemente mononuclear, com granulócitos eosinófilos na lâmina própria; associam-se diminutas erosões superficiais (2-3mm), edema e hipotrofia da mucosa com espessamento, encurtamento e inversão parcial da relação vilosidade/cripta; larvas rabditóides e ovos nas criptas (Figura 3). No intestino grosso o infiltrado inflamatório é multifocal e composto

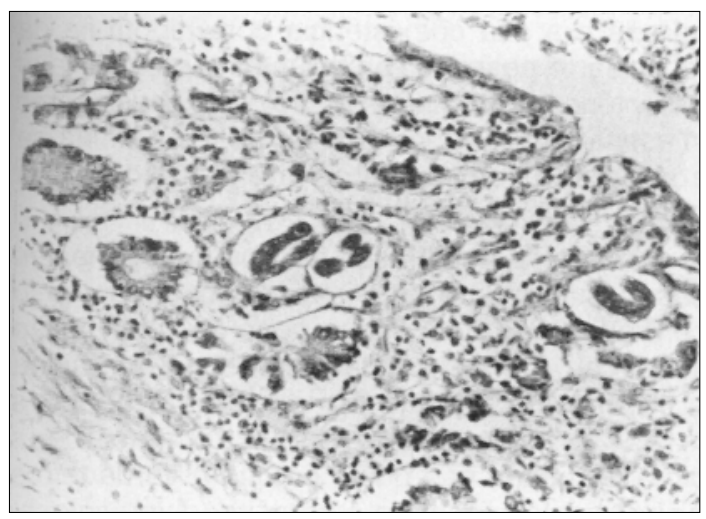

Figura 3 - Estrongiloidíase do intestino delgado, com parasitismo de superfície; larvas nas criptas. HE, 100X.

de células mononucleares e gigantes, além de eosinófilos, freqüentemente formando granulomas epitelióides frouxos, além de áreas de neoformação conjuntivo-vascular, em todas camadas da parede (Figura 4). As larvas ou restos de larvas em penetração (filariformes)

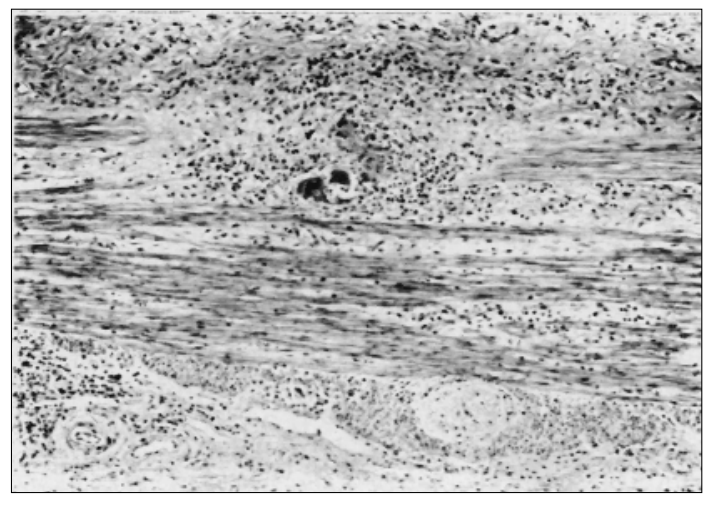

Figura 4 - Estrongiloidíase do intestino grosso, com parasitismo de penetração; reação gigantocelular em presença de larva e neoformação conjuntivo-vascular, $H E, 100 X$. são observadas isoladas ou em relação com o processo inflamatório.

\section{DISCUSSÃO}

O timoma é raro, embora referido como o tumor mais freqüente do mediastino ânterosuperior. São considerados dois tipos, o não invasivo, encapsulado ou circunscrito ( $2 / 3$ dos casos) e o invasivo, em geral com implantação pleural, raramente determinando metástases pela via linfática ou hematogênica; ocorrem, especialmente, na $5^{\underline{a}}$ e $6^{\underline{a}}$ décadas da vida8 17.

Na classificação destes tumores, ora se aplica como critério a proporção células epiteliais neoplásicas e linfócitos 9 , presentes em $95 \%$ dos casos,ora as características das células epiteliais, incluindo sua origem cortical,medular ou mista, ambas controvertidas 101317 .

Admite-se pior prognóstico para os de origem cortical, compostos de células poligonais (timoma cortical, tipo I), o contrário ocorre com os medulares, em geral de células fusiformes, considerados benignos, ocupando posição intermediária os mistos. A malignidade é demonstrada pela invasão e ou metástases, presentes em 35\% dos casos. Apenas 5\% dos tumores do timo não revelam qualquer dúvida quanto a malignidade, representando os carcinomas tímicos (timoma maligno tipo II), por alguns considerado como entidade distinta dos timomas 17 .

Cerca de $50 \%$ dos casos são assintomáticos e descobertos acidentalmente ao $\mathrm{Rx}$, quando de cirurgia para esclarecimento de massa mediastinal, ou na necropsia9. Apresentam sintomas por compressão (dor torácica, dispnéia, tosse), ou, em certo número de casos (25 a $50 \%$ ), conseqüentes a doenças sistêmicas (síndromes paratímicas), relacionadas a fenômenos autoimunes, com anormalidades ou deficiência de linfócitos T supressores. Destacam-se a myastenia gravis (em torno de $30 \%$ dos casos), hipoplasia pura de células vermelhas $(5 \%)$ e hipogamaglobulinemia $(5 \%)$, que podem vir associadas17 18. A hipogamaglobulinemia é acompanhada de total ausência de eosinófilos na medula óssea e sangue periférico, além de insuficiência da imunidade humoral e celular.

No caso apresentado não se suspeitou do diagnóstico do timoma; algumas queixas iniciais (tosse, adinamia e emagrecimento), inespecíficas, são relatadas como forma de apresentação do 
tumor em uma minoria dos casos9. A massa obervada ao Rx não foi bem definida, incluindo a sua posição mediastinal. Das síndromes paratímicas, a análise retrospectiva indica a probabilidade de hipogamaglobulinemia e, talvez, hipoplasia de células vermelhas. Não se aventou da hipótese de estrongiloidíase, inexistindo referência a exame parasitológico de fezes.

As larvas infectantes (filariformes) do Strongyloides stercoralis na presença de imunossupressão natural ou induzida, particularmente com o uso de corticosteróides, podem invadir maciçamente a parede do intestino grosso, alcançar os pulmões (hiperinfecção) ou todo o organismo (estrongiloidíase disseminada); em ambos os casos verdadeira exacerbação do ciclo de auto-infecção. A condição apresenta alta mortalidade, em parte por não ser reconhecida e tratada141112 15.

É freqüente a associação de bacteremia persistente por microorganismos entéricos, como conseqüência da translocação bacteriana intestinal, excreção da bactéria pelo trato intestinal da larvas migrantes ou aderência da bactéria a sua parede. Esses mecanismos explicariam a ocorrência de pneumonia, leptomeningite e outras infecções, além de choque séptico, refratários à terapêutica antibiótica, mantida a parasitose 415.

O mecanismo de defesa contra o verme está relacionado com a imunidade celular, especialmente aos linfócitos $\mathrm{T}$, embora hajam outros fatores envolvidos; a sua destruição é determinada pela ação dos eosinófilos, macrófagos e linfócitos 12 . A eosinofilia é bastante significativa, de acordo com o grau de infecção, e sua ausência ou queda está ligada a quadros graves da parasitose, ressalvada sua redução por infecções piogênicas associadas, uso de corticosteróides ou, talvez, pelo aumento de sua migração para os tecidos 31215 .

A imunidade humoral nas infecções helmínticas talvez auxilie na fixação ou resposta celular ao parasito. A gravidade da estrongiloidíase em pacientes com hipogamaglobulinemia indica sua participação significativa ${ }^{16}$. Na estrongiloidíase disseminada observam-se baixos níveis de $\operatorname{lgE}$ total e resposta IgE específica mínima, o contrário sucedendo nas formas crônicas. Os anticorpos IgG parasito-específicos não parecem exercer papel protetor contra a disseminação da parasitose ou indicador da gravidade da doença.
Há quem admita a necessidade de interação entre os eosinófilos e anticorpos IgE na prevenção da disseminação larvária 3 .

No caso em estudo a necropsia demonstrou estrongiloidíase intestinal grave, com parasitismo de superfície no intestino delgado e de penetração (forma invasiva) no grosso, onde se observaram larvas desde a mucosa até a serosa. A neoformação conjuntiva descrita no intestino grosso poderia ser responsável por rigidez da parede e a sua coexistência com hipotrofia da muscular e possível comprometimento do plexo mioentérico, justificariam distúrbios do peristaltismo intestinal1 12. O quadro descrito assemelha-se ao relatado como enterocolite granulomatosa eosinofílica5.

A diarréia, manifestação dominante nestes casos, surgiu durante a internação, sendo, pelo contrário, relatado longo período de constipação intestinal. A hipomotilidade intestinal permitiria a permanência mais prolongada das larvas infectantes, tal como descrito em outras circunstâncias, nas quais se criam verdadeiros nichos ecológicos para o parasito (diverticulose, gastroenteroanastomose, megacólon, etc.). Por seu turno, as alterações da parede intestinal pela estrongiloidíase inibiriam a motilidade da víscera, criando-se um círculo vicioso 12 .

As repercussões pulmonares foram relacionadas com broncopneumonia grave, comum em tais casos. A pesquisa negativa para Strongyloides stercoralis nos pulmões não afasta sua participação direta ou indireta no processo 15 , devendo ser assinalado o componente hemorrágico, presente no caso, e descrito na estrongiloidíase 419.

Não se comprovou uma hipogamaglobulinemia, porém constataram-se baixos níveis de globulinas, eosinopenia e, posteriormente, ausência de eosinófilos.A possibilidade de aplasia de células vermelhas sugerida pelo índice hematimétrico, sem qualquer etiologia aparente, não foi investigada; não existe estudo da medula óssea e contagem de reticulócitos no sangue periférico. Essa aplasia está presente em $35 \%$ dos timomas acompanhados de hipogamaglobulinemia.

O estudo do caso e a análise da literatura não permitiu estabelecer ligação indiscutível entre a estrongiloidíase grave e a já reconhecida imunodepressão relacionada ao timoma. Além disso, há dúvida se o defeito imunitário seria secundário ao tumor tímico ou se esse representaria resposta compensadora à deficiência de fator regulador imune, ainda mal 
definido, talvez relacionado, também, com maior freqüência de outras neoplasias primárias ou certas doenças associadas (miocardite granulomatosa idiopática, lupo eritematoso sistêmico, doença de Addison). A propósito, a timectomia, freqüentemente, não determina o desaparecimento da síndrome paratímica, especialmente a hipogamaglobulinemia14; por outro lado, a síndrome paratímica pode surgir depois da ressecção do timoma, às vezes após

\section{REFERÊNCIAS BIBLIOGRÁFICAS}

vários anos.

1. De Paola D. Patologia da Estrongiloidíase, Rio de Janeiro, 1961, $143 \mathrm{p}$.

2. Dias RMDS, Mancini ACS, Torres DMAGV, Vellosa SAG, Silva MIPG, Silva RM, Corrêa MOA, Coletti C. Ocorrência de Strongyloides stercoralis em pacientes portadores da síndrome de imunodeficiência adquirida (AIDS). Revista do Instituto de Medicina Tropical de São Paulo 34:15-17, 1992.

3. Genta RM, Douce RW, Walzer PD. Diagnostic implications of parasite-specific immune responses in immunocompromised patients with strongyloidiasis. Journal of Clinical Microbiology 23:1099-1103, 1986.

4. Gomes MC. Mecanismos patológicos relacionados à auto-endo-infecção na estrongiloidose humana fatal. Revista de Patologia Tropical 9:165-261, 1980.

5. Gutierrez Y, Bhatia P, Garbadanawa ST, Dobson JR, Wallace TM, Carey TE. Strongyloides stercoralis eosinophilic granulomatous enterocolitis. The American Journal of Surgical Pathology 20:603-612, 1996.

6. Kyle LH, McKay DG, Sparling Jr HJ. Strongyloidiasis. Annals of Internal Medicine 29:1014-1042, 1948.

7. Kirkpatrick $\mathrm{CH}$, Windhorst D. Mucocutaneous candidiasis and thymoma.The American Jounal of Medicine 66:939-945, 1979.

8. Levine GD, Rosai J. Thymic hyperplasia and neoplasia: a review of current concepts Human Pathology 5:495-515, 1978.

9. Lewis JE, Wick MR, Scheithauer BW, Bernatz PE, Taylor WF. Thymoma. A clinicopathological review. Cancer 60:2727-2743, 1987.

10. Marino M, Müller-Hermelink HK. Thymoma and thymic carcinoma. Virchow Archives (Pathological Anatomie). 407:119-149, 1985.

11. Pires ML, Dreyer G. Revendo a importância do Strongyloides stercoralis. Revista do Hospital das Clínicas da Faculdade de Medicina de São Paulo 48:175-182, 1993.

12. Purtillo DT, Meyers WM, Connor DH. Fatal strongyloidiasis in immunosupressed patients. The American Journal of Medicine 56:488-493, 1974.

13. Ricci C, Rendina EA, Pescarmona EQ, Venuta F, Ditolla R, Pruco L, Baroni CD. Correlations between histological type, clinical behaviour, and prognosis in thymoma. Thorax 44:455-460, 1989.

14. Rosenow EC, Hurley BT. Disorders of the thymus. Archives of Internal Medicine 144:763-770, 1984.

15. Scowden EB, Schaffner N, Stone WJ. Overwhelming strongyloidiasis. An unappreciated opportunistic infection. Medicine 57:527-544, 1978.

16. Shelhamer JH, Neva FA, Finn RD. Persistent strongyloidiasis in an immunodeficient patient. The American Journal of Tropical Medicine and Hygiene 31:746-751, 1982.

17. Shimosato $Y$, Mukai K. Tumors of the mediastinum. Atlas of Tumor Pathology. Third Series, Fascicle 21, Washington, DC, Armed Forces Institute of Pathology, 1997.

18. Souadjian JV, Enriquez P, Silverstein MN, Pépin JM. The spectrum of diseases associated with thymoma. Archives of Internal Medicine 134:374-379, 1974.

19. Von Lichtenberg F. Pathology of Infectious Diseases. New York,Raven Press Ltd., 1991. 